\title{
Histone deacetylase inhibition facilitates massed pattern-induced synaptic plasticity and memory
}

\author{
Kiran Pandey, ${ }^{1,2}$ Kaushik P. Sharma, ${ }^{1,2}$ and Shiv K. Sharma ${ }^{1}$ \\ ${ }^{1}$ National Brain Research Centre, Manesar, Haryana 122051, India
}

\begin{abstract}
Massed training is less effective for long-term memory formation than the spaced training. The role of acetylation in synaptic plasticity and memory is now well established. However, the role of this important protein modification in synaptic plasticity induced by massed pattern of stimulation or memory induced by massed training is not well understood. Here we show that increasing the level of acetylation enhances long-term potentiation induced by massed pattern of high frequency stimulation. Furthermore, enhancing acetylation level facilitates long-term memory by massed training. Thus, increasing acetylation level facilitates synaptic plasticity and memory by massed patterns.
\end{abstract}

[Supplemental material is available for this article.]

In a multitrial task, memory formation displays sensitivity to the pattern of training trials. Memory formation is more efficient when the training trials are spaced in time than when they are massed together with little or no temporal spacing. Better memory formation by spaced training compared with massed training is commonly referred to as the spacing effect. An important feature of the spacing effect is that the number of trials remains the same, only the temporal spacing between the trials is different between the two training paradigms. After being first described by Ebbinghaus, spacing effect has been observed in invertebrates as well as vertebrates, and across different memory tasks (Naqib et al. 2012; Philips et al. 2013). For example, in Aplysia, Carew et al. (1972) showed that spaced training leads to longer-lasting memory for habituation than the massed training. Sutton et al. (2002) found that massed training fails to induce long-term memory (LTM) for sensitization, but the spaced training produces LTM. In the mammalian system, Josselyn et al. (2001) showed that LTM formation in a fear-conditioning task is sensitive to the pattern of training. Similarly, spatial memory formation displays sensitivity to the pattern of training (Spreng et al. 2002; Commins et al. 2003). The spacing effect phenomenon has been observed in other systems also including humans (Philips et al. 2013). Spaced training is superior to massed training in stressful as well as nonstressful memories (Josselyn et al. 2001; Anderson et al. 2008). In addition, spaced trials are more effective compared with massed trials for extinction memory (Urcelay et al. 2009).

Long-term potentiation (LTP) is considered a promising cellular mechanism of memory formation (Bliss and Collingridge 1993; Martinez and Derrick 1996). LTP also shows pattern sensitivity. Scharf et al. (2002) found that greater LTP is induced with spaced tetanic stimulation than with same number of massed tetanic stimuli. Ajay and Bhalla (2004) demonstrated that time intervals of 5-10 min between tetanic stimuli induce larger LTP than the same number of stimulations applied with 10-20-sec inter-tetanus interval. A recent study showed superiority of spaced $\theta$ burst stimulation in LTP formation that involves recruitment of additional synapses (Kramár et al. 2012). The pattern sensitivity of synaptic plasticity has also been demonstrated in Aplysia (Mauelshagen et al. 1998).

\footnotetext{
${ }^{2}$ These authors contributed equally to this work.

Corresponding author: sharmas@nbrc.ac.in

Article is online at http://www.learnmem.org/cgi/doi/10.1101/Im.039289. 115.
}

Regulation of signaling molecules plays important roles in synaptic plasticity and memory. Studies have shown pattern sensitivity of different molecular processes relevant for these events (Ye et al. 2008; Akalal et al. 2010; Kim et al. 2010; Pai et al. 2013). Wu et al. (2001) showed that spaced depolarizationinduced activation of extracellular signal-regulated kinase (ERK) is longer lasting than the ERK activation induced by massed pattern of stimulation. Farah et al. (2009) showed that membrane translocation of protein kinase $\mathrm{C}$ is differentially regulated by massed and spaced application of serotonin to Aplysia neurons (Farah et al. 2009).

The role of acetylation in synaptic plasticity and memory is now well recognized (Levenson and Sweatt 2005; Sharma 2010). Increasing the level of acetylation by inhibition of histone deacetylases (HDAC) enhances LTP in the hippocampal slices and LTM in contextual fear conditioning task (Levenson et al. 2004). Further, HDAC inhibitor reduces the threshold of training for LTM formation in novel object recognition task (Stefanko et al. 2009), and facilitates spatial memory in water maze task (Dagnas et al. 2015). Several other studies have also shown that acetylation is an important modification in synaptic plasticity and memory (e.g., Guan et al. 2009; Bousiges et al. 2010; Dagnas and Mons 2013). However, the role of acetylation in massed pattern-induced synaptic plasticity or memory is not well understood. In this study, we show that increasing acetylation level by HDAC inhibition enhances LTP and memory induced by massed patterns. Findings of this study have previously been published in abstract form (Sharma et al. 2014).

We first examined LTP profile in the hippocampal slices induced by massed and spaced patterns of stimulations. Detailed Materials and Methods section is provided as Supplemental Material. The input/output curve is shown in Supplemental Figure 1. LTP was induced by stimulating the Schaffer collateral pathway using four bursts (each burst consisted of 100 stimulations at $100 \mathrm{~Hz}$ ), and the field excitatory postsynaptic potential (fEPSP) was recorded in the CA1 region. For spaced stimulation, the four bursts were applied at 5-min inter-burst interval whereas

\footnotetext{
C 2015 Pandey et al. This article is distributed exclusively by Cold Spring Harbor Laboratory Press for the first 12 months after the full-issue publication date (see http://learnmem.cshlp.org/site/misc/terms.xhtml). After 12 months, it is available under a Creative Commons License (AttributionNonCommercial 4.0 International), as described at http://creativecommons. org/licenses/by-nc/4.0/.
} 
for massed stimulation, the inter-burst interval was $20 \mathrm{sec}$ (Scharf et al. 2002). In both stimulation paradigms, the same number of stimuli were delivered. Only the time interval between bursts of stimulation was varied between the massed and spaced conditions. Figure $1 \mathrm{~A}$ shows that LTP was induced by both patterns of stimulations. However, consistent with previous reports (Scharf et al. 2002; Ajay and Bhalla 2004), the magnitude of LTP induced by massed pattern of stimulation was smaller than that of LTP induced by spaced pattern (fEPSP slope, \% baseline, spaced, $131.37 \pm 3.29$; massed, $113.64 \pm 3.93$; 109 min after first stimulation, $P<0.01$ ). Thus, massed pattern of tetanic stimulation induces LTP that is of lesser magnitude than LTP induced by spaced pattern of stimulation.

We next asked whether the extent of LTP induced by massed stimulation could be enhanced by increasing the level of acetyla-
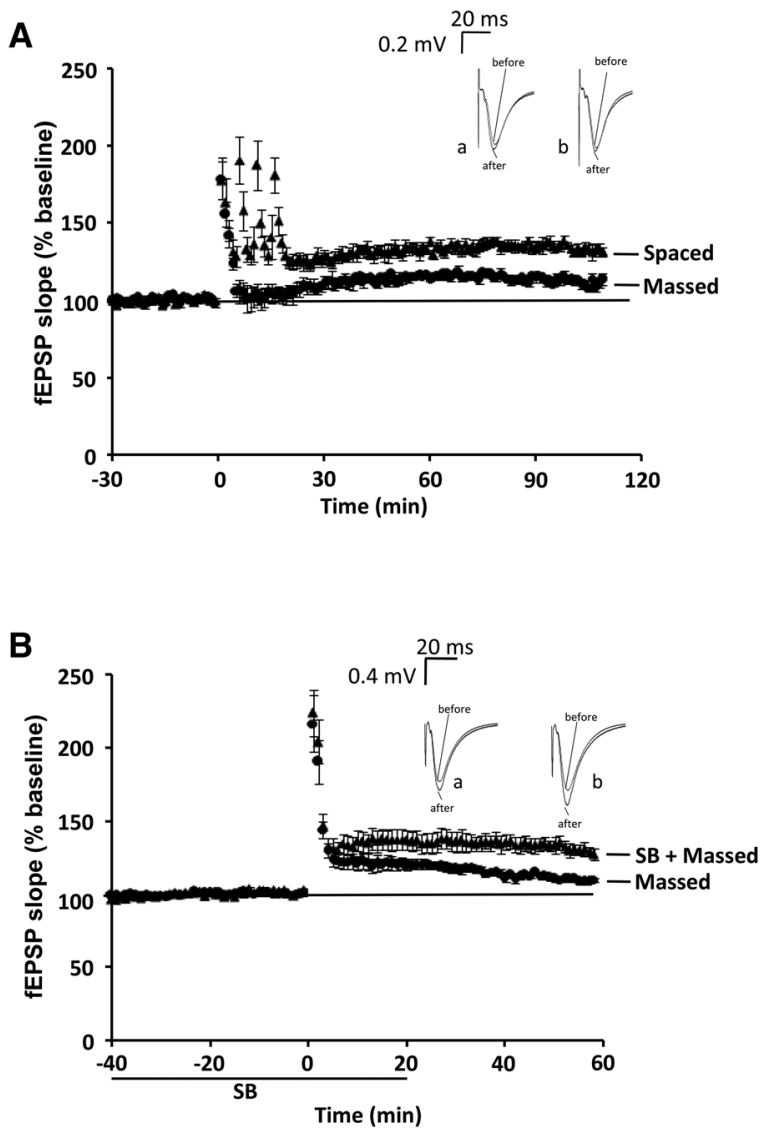

Figure 1. Pattern sensitivity of long-term potentiation (LTP) and the effect of histone deacetylase inhibition on massed pattern-induced LTP. (A) Spaced tetanic stimuli induce higher extent of LTP than massed tetanic stimuli. The slices were given four bursts (each burst consisted of 100 stimuli at $100 \mathrm{~Hz}$ ) of stimulation with inter-burst interval of either 5 min (Spaced) or $20 \mathrm{sec}$ (Massed). Both stimulation paradigms induced synaptic potentiation that lasted for at least $109 \mathrm{~min}$. However, LTP induced by spaced tetanic stimulation was higher in magnitude than the LTP induced by massed tetanic stimulation $(n=5$, both groups). The recording traces before $(-2 \mathrm{~min})$ and after $(109 \mathrm{~min})$ first stimulation in spaced (a) and massed (b) conditions are also shown. (B) Histone deacetylase inhibition enhances LTP by massed tetanic stimulation. LTP was induced by four bursts (each burst consisted of 100 stimuli at 100 $\mathrm{Hz}$ ) of stimulation with $20-\mathrm{sec}$ inter-burst interval in the presence or absence of histone deacetylase inhibitor, sodium butyrate (SB). SB enhanced LTP induced by massed tetanic stimulation $(n=5$, both groups). Recording traces before $(-2 \mathrm{~min})$ and after $(58 \mathrm{~min})$ first tetanic stimulation in the absence (a) or presence (b) of SB are also shown. tion. Sodium butyrate (SB) is a histone deacetylase inhibitor that has been used in previous studies to enhance acetylation level and study the effects on LTP and memory (e.g., Levenson et al. 2004; Itzhak et al. 2013). The input/output curve is shown in Supplemental Figure 2. Slices were perfused with SB for $1 \mathrm{~h}$, starting $40 \mathrm{~min}$ before massed tetra-burst stimulation. The results (Fig. $1 B$ ) show that SB enhanced LTP induced by massed stimulation (fEPSP slope, \% baseline, massed, $110.03 \pm 1.33$; SB + massed, $127.14 \pm 3.91,58 \mathrm{~min}$ after first stimulation, $P<0.01)$. The slices showed similar input/output relationship in the absence or presence of SB (Supplemental Fig. 3A). Moreover, SB did not affect baseline synaptic response in the absence of LTP-inducing stimuli (fEPSP slope, \% baseline, 92.34 $\pm 3.25,91-100$ min after starting SB application, $P>0.05$; Supplemental Fig. 3B). Thus, increasing the level of acetylation enhances the extent of LTP induced by massed pattern of tetanic stimulation.

In the next set of experiments, we examined memory induced by massed or spaced patterns of training, and the effects of histone deacetylase inhibition. Using water maze, previous studies have shown that spaced training spread over a number of days is more effective for LTM formation than the massed training conducted in a single day (Spreng et al. 2002; Commins et al. 2003). We compared the effect of spaced and massed trainings on memory formation in water maze task by providing both patterns of training in a single day. Figure $2 \mathrm{~A}$ shows that there was a decrease in escape latency across the training trials with both training paradigms. Both groups of animals showed similar escape latency by the end of training suggesting similar extent of learning (latency in the last block of training, spaced-trained = $14.40 \pm 2.34 \mathrm{sec}$; massed-trained $=12.98 \pm 1.45 \mathrm{sec}, P>0.60$ ). However, there was a clear difference in escape latency during the probe trial for LTM conducted $24 \mathrm{~h}$ after training such that the spaced-trained animals reached the platform area sooner than the massed-trained animals (Fig. 2A, latency in the LTM test, spaced-trained $=22.0 \pm 7.16 \mathrm{sec}$; massed-trained $=42.55 \pm$ $6.89 \mathrm{sec}, P<0.03)$. During the LTM test, the amount of time the animals spent in different quadrants and annulus (former platform area) crossings were also analyzed. The spaced-trained animals spent more time in the platform quadrant (Q4) than the massed-trained animals (Fig. 2B, spaced-trained $=22.45 \pm 1.88$ sec; massed-trained $=15.18 \pm 1.40 \mathrm{sec}, P<0.01$ ). Furthermore, the spaced-trained animals crossed the annulus more times than the massed-trained animals (Fig. 2C, spaced-trained $=1.82 \pm$ 0.47 ; massed-trained $=0.82 \pm 0.26, P<0.05$ ). The representative track plots during the LTM test are presented in Figure 2D.

We analyzed the swimming speed of animals trained under both paradigms. Except a few training trials, the speed of animals in both the groups was similar during training and during the LTM test (Supplemental Fig. 4). Collectively, the results show that spaced training leads to better LTM than massed training when both kinds of trainings are provided in a single day.

We next sought to determine whether HDAC inhibition could facilitate LTM with massed training in the water maze task. Similar to previous studies (e.g., Itzhak et al. 2013), we used intraperitoneal injection of SB to study its effect on memory formation by massed training. During training, both massed and SB + massed groups showed decrease in escape latency. Both groups showed similar escape latency during the last set of trials (Fig. $3 \mathrm{~A}$, average latency of the last five training trials, massedtrained $=13.12 \pm 1.83 \mathrm{sec} ; \mathrm{SB}+$ massed-trained $=14.62 \pm 2.04$ sec, $P>0.5)$ suggesting that $\mathrm{SB}$ does not affect learning ability. Despite being given massed training, SB-treated animals presented shorter escape latency during the probe trial for LTM conducted 24 $\mathrm{h}$ after training (Fig. 3A, latency in the LTM test, massed-trained $=$ $52.67 \pm 3.44$ sec; $\mathrm{SB}+$ massed-trained $=31.15 \pm 5.69 \mathrm{sec}, P<$ 0.01). During the LTM test, the amount of time the animals 
A

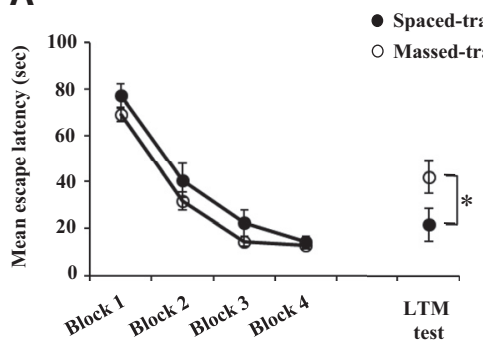

B

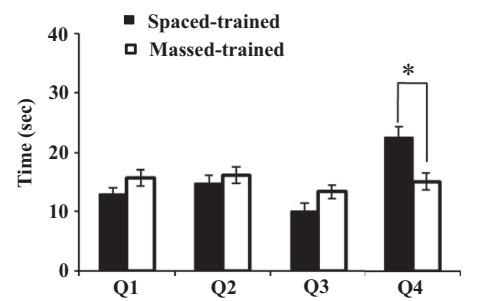

D

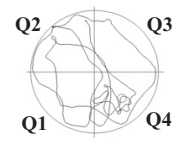

Spaced-trained

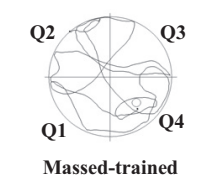

Figure 2. Performance of massed- and spaced-trained animals in the water maze task. $(A)$ The animals were given either spaced or massed training ( $n=11$, both groups) in the water maze. The inter-block interval in the spaced group was $2 \mathrm{~h}$ and inter-block interval in the massed group was 1 min. Each block consisted of 5 trials with 1 min inter-trial interval. Spaced- as well as massed-trained animals showed decrease in latency to reach the platform over the course of training. During the long-term memory test (LTM test), the spaced-trained animals took significantly less time to reach the platform area than the massed-trained animals. Average of five trials is plotted for each block. $(B)$ The animals that received spaced training spent significantly more time in the platform quadrant (Q4) than the massed-trained animals during the long-term memory test (LTM test in A). (C) The spaced-trained animals showed significantly more annulus crossings than the massed-trained animals during the longterm memory test (LTM test in $A$ ). (D) The representative track plots during the long-term memory test (LTM test in $A$ ) are shown for both groups. Asterisks denote significant difference $(P<0.05)$.

spent in different quadrants and annulus crossings were also analyzed. The SB + massed-trained animals spent more time in the platform quadrant $(\mathrm{Q} 4)$ than the massed-trained animals, although the difference did not reach statistical significance (Fig. 3B, massed-trained $=16.27 \pm 1.80 \mathrm{sec}$; $\mathrm{SB}+$ massed-trained $=20.92 \pm 2.47 \mathrm{sec}, P=0.13)$. In addition, there was a significant difference in the number of annulus crossings between the two groups (Fig. 3C, massed-trained $=0.47 \pm 0.19 ; \quad S B+$ massedtrained $=1.85 \pm 0.37, P<0.01$ ). The representative track plots during the LTM test are presented in Figure 3D. We compared the weight gain and swim speed also of the animals of both groups. SB did not affect body weight of the animals across the experimental period (Supplemental Fig. 5A). In addition, massedtrained and SB + massed-trained animals showed similar swim speed (Supplemental Fig. 5B). Collectively, the results show that histone deacetylase inhibition facilitates LTM by massed training.

Using hippocampal slices, we have examined LTP induced by massed or spaced patterns of high frequency stimulation. Consistent with previous studies (Scharf et al. 2002; Ajay and
Bhalla 2004), we found that spaced stimulation-induced LTP was higher in magnitude than LTP induced by massed pattern of stimulation. Inhibition of HDAC that results in increase in acetylation level (Itzhak et al. 2013) has served as a useful tool to investigate the role of acetylation in synaptic plasticity and memory. We found that inhibition of histone deacetylases with SB enhanced LTP induced by massed stimulation. The HDAC inhibitor did not affect baseline synaptic response in the absence of LTP-inducing stimuli. In addition, input-output curve was also unaffected by sodium butyrate. These results are consistent with the finding of Levenson et al. (2004), who found that LTP induced by $2,100-\mathrm{Hz}$ trains separated by $20 \mathrm{sec}$ is enhanced by HDAC inhibition. The lack of effect of deacetylase inhibition on basal response is also consistent with the findings of Levenson et al. (2004) and suggest that the deacetylase inhibitor enhances potentiation by affecting the processes relevant for LTP.

At the behavioral level, previous studies have shown that spaced training produces better memory in several tasks. In water maze task, spaced training spread over a number of days is more effective in LTM formation than massed training conducted in a single day (Spreng et al. 2002; Commins et al. 2003). We

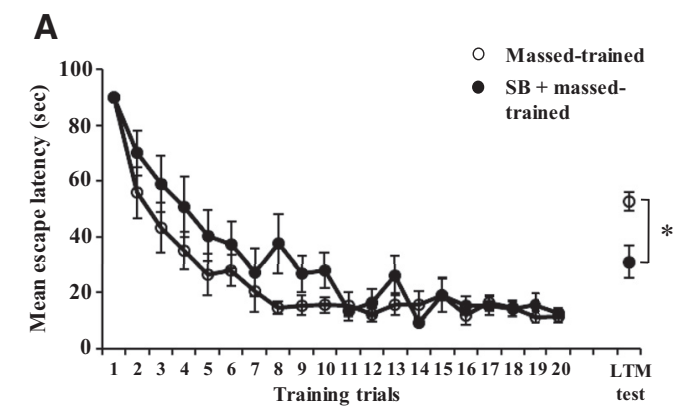

B

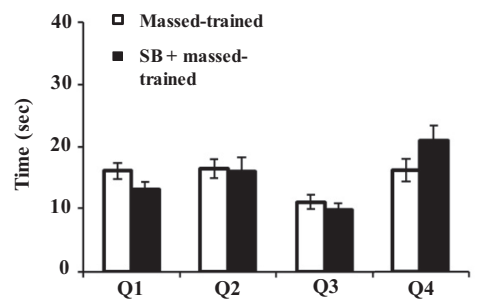

D

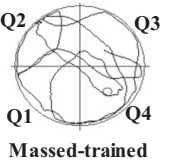

C

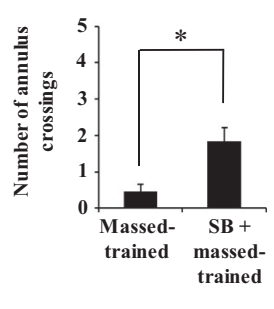

Figure 3. Sodium butyrate (SB) facilitates long-term memory formation by massed training. The animals were given massed training in the water maze task. (A) Both groups (SB + massed-trained, $n=13$; massedtrained, $n=15$ ) showed reduction in escape latency over the course of training. During the long-term memory test (LTM test), the SB + massedtrained animals reached the platform area sooner than the massed-trained animals. ( $B$ ) During the long-term memory test (LTM test in $A$ ), the time spent in different quadrants (Q4 = platform quadrant) is shown for massed-trained and SB + massed-trained animals. (C) During the longterm memory test (LTM test in $A$ ), the SB + massed-trained animals showed significantly more annulus crossings than massed-trained animals. (D) The representative track plots during the long-term memory test (LTM test in $A$ ) are shown for both groups. Asterisks denote significant difference $(P<0.05)$. 
conducted spaced and massed training in a single day to allow better comparison of both the training paradigms on memory formation. Our results showed that massed training is less effective in inducing LTM than the spaced training when both patterns of trainings are given in a single day. Since LTP is considered a cellular mechanism of memory, and we found that HDAC inhibition facilitates LTP, we next asked whether increasing acetylation level has any effect on memory formation by massed training. We found that inhibition of HDAC facilitated LTM by massed training. The massed and SB + massed groups showed significant difference in two measures, latency to reach the former platform area and the number of annulus crossings, although in one measure, time spent in platform quadrant, the difference between the two groups was not statistically significant. It is possible that other training protocols or SB treatment conditions may show a difference in this measure also. The deacetylase inhibitor had no effect on the weight of the animals during the experimental period. In addition, massed and SB + massed groups showed similar swim speed. Collectively, the results suggest that deacetylase inhibition facilitates memory with massed training by affecting processes involved in LTM formation. Previous studies have shown that trichostatin A as well as SB enhance LTP and memory (Levenson et al. 2004; Vecsey et al. 2007). It would be good to confirm the enhancing effects of SB on massed pattern-induced LTP and memory with another HDAC inhibitor.

It has been shown previously that enhancement of LTP by HDAC inhibitor requires transcriptional activity (Levenson et al. 2004; Vecsey et al. 2007). The beneficial effects of deacetylase inhibition on LTP by massed stimulation and memory by massed training may be related to transcriptional facilitation. Since histone acetylation is associated with transcriptional activation (Berger 2007; Kouzarides 2007), increased histone acetylation may facilitate the transcription of plasticity-related genes, which may contribute to enhancement in LTP and memory. A recent study has shown that SB increases the expression of brainderived neurotrophic factor (BDNF, Intlekofer et al. 2013). These authors showed also that the facilitatory role of SB on memory formation requires BDNF. The role of BDNF in memory formation is well established (Lu et al. 2008; Cunha et al. 2010). Thus, it is possible that induction of BDNF and other plasticityrelated genes plays an important role in LTM formation by massed training when acetylation level is enhanced by deacetylase inhibition.

In summary, using electrophysiological and behavioral approaches, we have shown that enhancing the level of protein acetylation by HDAC inhibition enhances LTP and memory by massed pattern of stimulation or training, respectively. These results also suggest that acetylation level plays an important role in determining the superiority of spaced stimulation on synaptic plasticity or spaced training on memory formation. Although HDAC inhibitors are known to increase acetylation of histones, these inhibitors have other targets also. The effects of sodium butyrate on synaptic plasticity and memory by massed pattern of stimulation or training may involve acetylation of proteins in addition to histones. It would be interesting to examine the molecular targets of deacetylase inhibitor that contribute to enhanced LTP by massed stimulation and better memory by massed training.

\section{Acknowledgments}

K.P and K.P.S. were recipients of fellowships from CSIR, India. This work was supported by a research grant from DBT, India and from core funds to NBRC from DBT, India. We thank Prof. Toshiya Manabe, University of Tokyo for providing training to Kaushik for LTP recording. We thank Dr. Upinder Bhalla of NCBS,
Bengaluru and Dr. B.S. Shankaranarayana Rao, NIMHANS, Bengaluru for teaching electrophysiological recording. We thank Prof. Neeraj Jain of NBRC for critically reading the manuscript.

Author contributions: K.P., K.P.S., and S.K.S. designed the study and wrote the manuscript. K.P.S. performed the electrophysiological experiments and data analysis. K.P. performed the behavioral experiments and data analysis.

\section{References}

Ajay SM, Bhalla US. 2004. A role for ERKII in synaptic pattern selectivity on the time-scale of minutes. Eur J Neurosci 20: 2671-2680.

Akalal DB, Yu D, Davis RL. 2010. A late-phase, long-term memory trace forms in the $\gamma$ neurons of Drosophila mushroom bodies after olfactory classical conditioning. J Neurosci 30: 16699-16708.

Anderson MJ, Jablonski SA, Klimas DB. 2008. Spaced initial stimulus familiarization enhances novelty preference in Long-Evans rats. Behav Processes 78: $481-486$.

Berger SL. 2007. The complex language of chromatin regulation during transcription. Nature 447: 407-412.

Bliss TV, Collingridge GL. 1993. A synaptic model of memory: long-term potentiation in the hippocampus. Nature 361: 31-39.

Bousiges O, Vasconcelos AP, Neidl R, Cosquer B, Herbeaux K, Panteleeva I, Loeffler JP, Cassel JC, Boutillier AL. 2010. Spatial memory consolidation is associated with induction of several lysine-acetyltransferase (histone acetyltransferase) expression levels and $\mathrm{H} 2 \mathrm{~B} / \mathrm{H} 4$ acetylationdependent transcriptional events in the rat hippocampus. Neuropsychopharmacology 35: 2521-2537.

Carew TJ, Pinsker HM, Kandel ER. 1972. Long-term habituation of a defensive withdrawal reflex in Aplysia. Science 175: 451-454.

Commins S, Cunningham L, Harvey D, Walsh D. 2003. Massed but not spaced training impairs spatial memory. Behav Brain Res 139: $215-223$.

Cunha C, Brambilla R, Thomas KL. 2010. A simple role for BDNF in learning and memory? Front Mol Neurosci 3: 1.

Dagnas M, Mons N. 2013. Region- and age-specific patterns of histone acetylation related to spatial and cued learning in the water maze. Hippocampus 23: 581-591.

Dagnas M, Micheau J, Decorte L, Beracochea D, Mons N. 2015. Post-training, intrahippocampal HDAC inhibition differentially impacts neural circuits underlying spatial memory in adult and aged mice. Hippocampus 25: 827-837.

Farah CA, Weatherill D, Dunn TW, Sossin WS. 2009. PKC differentially translocates during spaced and massed training in Aplysia. J Neurosci 29: $10281-10286$.

Guan JS, Haggarty SJ, Giacometti E, Dannenberg JH, Joseph N, Gao J, Nieland TJ, Zhou Y, Wang X, Mazitschek R, et al. 2009. HDAC2 negatively regulates memory formation and synaptic plasticity. Nature 459: $55-60$.

Intlekofer KA, Berchtold NC, Malvaez M, Carlos AJ, McQuown SC, Cunningham MJ, Wood MA, Cotman CW. 2013. Exercise and sodium butyrate transform a subthreshold learning event into long-term memory via a brain-derived neurotrophic factor-dependent mechanism. Neuropsychopharmacology 38: 2027-2034.

Itzhak Y, Liddie S, Anderson KL. 2013. Sodium butyrate-induced histone acetylation strengthens the expression of cocaine-associated contextual memory. Neurobiol Learn Mem 102: 34-42.

Josselyn SA, Shi C, Carlezon WA Jr, Neve RL, Nestler EJ, Davis M. 2001. Long-term memory is facilitated by cAMP response element-binding protein overexpression in the amygdala. J Neurosci 21: 2404-2412.

Kim M, Huang T, Abel T, Blackwell KT. 2010. Temporal sensitivity of protein kinase a activation in late-phase long term potentiation. PLoS Comput Biol 6: e1000691.

Kouzarides T. 2007. Chromatin modifications and their function. Cell 128: $693-705$.

Kramár EA, Babayan AH, Gavin CF, Cox CD, Jafari M, Gall CM, Rumbaugh G, Lynch G. 2012. Synaptic evidence for the efficacy of spaced learning. Proc Natl Acad Sci 109: 5121-5126.

Levenson JM, Sweatt JD. 2005. Epigenetic mechanisms in memory formation. Nat Rev Neurosci 6: 108-118.

Levenson JM, O'Riordan KJ, Brown KD, Trinh MA, Molfese DL, Sweatt JD. 2004. Regulation of histone acetylation during memory formation in the hippocampus. J Biol Chem 279: 40545-40559.

Lu Y, Christian K, Lu B. 2008. BDNF: a key regulator for protein synthesis-dependent LTP and long-term memory? Neurobiol Learn Mem 89: $312-323$.

Martinez JL Jr, Derrick BE. 1996. Long-term potentiation and learning. Annu Rev Psychol 47: 173-203.

Mauelshagen J, Sherff CM, Carew TJ. 1998. Differential induction of long-term synaptic facilitation by spaced and massed applications of 
serotonin at sensory neuron synapses of Aplysia californica. Learn Mem 5: $246-256$.

Naqib F, Sossin WS, Farah CA. 2012. Molecular determinants of the spacing effect. Neural Plast 2012: 581291.

Pai TP, Chen CC, Lin HH, Chin AL, Lai JS, Lee PT, Tully T, Chiang AS. 2013. Drosophila ORB protein in two mushroom body output neurons is necessary for long-term memory formation. Proc Natl Acad Sci 110: $7898-7903$.

Philips GT, Kopec AM, Carew TJ. 2013. Pattern and predictability in memory formation: from molecular mechanisms to clinical relevance. Neurobiol Learn Mem 105: 117-124.

Scharf MT, Woo NH, Lattal KM, Young JZ, Nguyen PV, Abel T. 2002. Protein synthesis is required for the enhancement of long-term potentiation and long-term memory by spaced training. J Neurophysiol 87: $2770-2777$.

Sharma SK. 2010. Protein acetylation in synaptic plasticity and memory. Neurosci Biobehav Rev 34: 1234-1240.

Sharma SK, Sharma KP, Pandey K. 2014. Effects of histone deacetylase inhibitor on massed pattern-induced synaptic plasticity and memory. Soc Neurosci Abstract 689.28.

Spreng M, Rossier J, Schenk F. 2002. Spaced training facilitates long-term retention of place navigation in adult but not in adolescent rats. Behav Brain Res 128: $103-108$.
Stefanko DP, Barrett RM, Ly AR, Reolon GK, Wood MA. 2009. Modulation of long-term memory for object recognition via HDAC inhibition. Proc Natl Acad Sci 106: 9447-9452.

Sutton MA, Ide J, Masters SE, Carew TJ. 2002. Interaction between amount and pattern of training in the induction of intermediate- and long-term memory for sensitization in Aplysia. Learn Mem 9: 29-40.

Urcelay GP, Wheeler DS, Miller RR. 2009. Spacing extinction trials alleviates renewal and spontaneous recovery. Learn Behav 37: 60-73.

Vecsey CG, Hawk JD, Lattal KM, Stein JM, Fabian SA, Attner MA, Cabrera SM, McDonough CB, Brindle PK, Abel T, et al. 2007. Histone deacetylase inhibitors enhance memory and synaptic plasticity via CREB:CBPdependent transcriptional activation. J Neurosci 27: 6128-6140.

Wu GY, Deisseroth K, Tsien RW. 2001. Spaced stimuli stabilize MAPK pathway activation and its effects on dendritic morphology. Nat Neurosci 4: 151-158.

Ye X, Shobe JL, Sharma SK, Marina A, Carew TJ. 2008. Small G proteins exhibit pattern sensitivity in MAPK activation during the induction of memory and synaptic facilitation in Aplysia. Proc Natl Acad Sci 105: 20511-20516.

Received June 2, 2015; accepted in revised form July 9, 2015. 


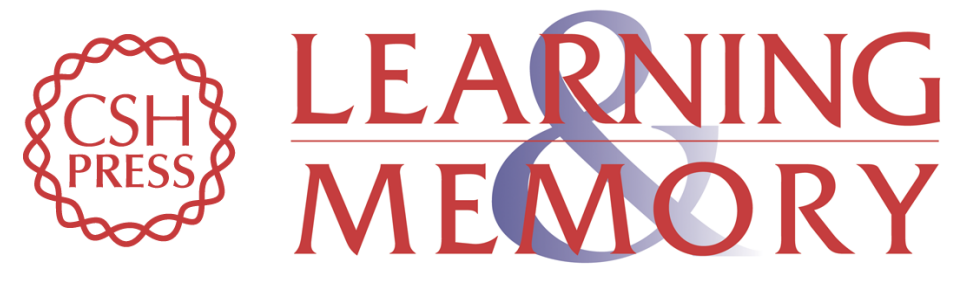

\section{Histone deacetylase inhibition facilitates massed pattern-induced synaptic plasticity and memory}

Kiran Pandey, Kaushik P. Sharma and Shiv K. Sharma

Learn. Mem. 2015, 22:

Access the most recent version at doi:10.1101/Im.039289.115

\section{Supplemental http://learnmem.cshlp.org/content/suppl/2015/09/10/22.10.514.DC1 Material}

References This article cites 36 articles, 12 of which can be accessed free at: http://learnmem.cshlp.org/content/22/10/514.full.html\#ref-list-1

Creative This article is distributed exclusively by Cold Spring Harbor Laboratory Press for the Commons first 12 months after the full-issue publication date (see

License http://learnmem.cshlp.org/site/misc/terms.xhtml). After 12 months, it is available under a Creative Commons License (Attribution-NonCommercial 4.0 International), as described at http://creativecommons.org/licenses/by-nc/4.0/.

Email Alerting Receive free email alerts when new articles cite this article - sign up in the box at the Service top right corner of the article or click here. 